\title{
Evaluation of pathology results of patients who underwent sleeve gastrectomy due to obesity
}

\author{
Mehmet Patmano, ${ }^{1}$ (1) Hasan Elkan, ${ }^{1}$ (1) Durmuş Ali Çetin, ${ }^{1}$ \\ Tufan Gümüş, ${ }^{1}$ (1) Gülsün Gülten² \\ 'Department of General Surgery, Şanlıurfa Training and Research Hospital, Şanlıurfa, Turkey \\ ${ }^{2}$ Department of Pathology, Şanlıurfa Training and Research Hospital, Şanlıurfa, Turkey
}

\begin{abstract}
Introduction: To evaluate the pathology results of patients who had laparoscopic sleeve gastrectomy due to obesity in our hospital and who did not have stomach complaints before the operation.

Materials and Methods: We retrospectively evaluated the pathology results of the patients who underwent laparoscopic sleeve gastrectomy for obesity between March 2018 and December 2018 at the Şanlıurfa Training and Resarch Hospital General Surgery Clinic. A total of 107 patients underwent surgery in our hospital.

Results: The mean age of the patients who underwent sleeve gastrectomy for morbid obesity between March 2018 and December 2018 was 36 (min: 20-max: 60 years). Eighty-one of the patients were female, and 26 were male. The mean BMI of the patients was $45.1(\mathrm{~min}: 37.2-\max : 63.4)$. When the pathology results of the patients were examined, the mean length of the specimen was $18.5 \mathrm{~cm}(\min : 14 \mathrm{~cm}-\max : 25 \mathrm{~cm})$, and the mean width was $4.2 \mathrm{~cm}$ (min: $3 \mathrm{~cm}$-max: $8 \mathrm{~cm}$ ). Normal gastric tissue was observed in $25(23.3 \%)$ patients. Chronic gastritis was found in $82(76.6 \%)$ patients. In $32(29.9 \%)$ patients with chronic gastritis, a Helicobacter pylori microorganism was positive. Metaplasia was observed in $4(3.7 \%)$ of the patients with chronic gastritis. A patient with suspected gastrointestinal stromal tumor was diagnosed as spindle cell mesenchymal lesion and chronic gastritis.

Conclusion: The number of Helicobacter pylori positive patients is related to the nutritional habits of our region. We believe that $\mathrm{H}$. pylori infections are not a risk of postoperative complications. However, we think that gastroscopy should be carried out in patients with preoperative gastric complaints.

Keywords: Helicobacter pylori; obesity; pathology; sleeve gastrectomy.
\end{abstract}

\section{Introduction}

Today, obesity is an epidemic problem especially in developed countries and it is the second most common preventable disease after smoking that causes death. Obesity is considered as a chronic disease that directly affects life time and comfort. ${ }^{[1,2]}$ Obesity is not just a weight problem. Obesity is rapidly increasing especially in young people and many chronic diseases as comorbidity are encountered at an earlier age. Venous circulatory disorders, coagulopathies and cardiac disorders, especially diabetes and hypertension, are the major ones. In $90 \%$ of patients 
non-alcoholic fatty liver and in $25 \%$ of non-alcoholic steatohepatitis are present. ${ }^{[3]}$ The increase in degenerative joint disease, colon and breast cancers can also be added to them. While $67 \%$ of the United States (USA) population is overweight or obese, this rate is $40-50 \%$ in most European countries. ${ }^{[4]}$

When obesity is not treated; it can cause health problems related to obesity, social and economic problems and negatively affect quality of life. Sustainable diet has a very important role in the treatment of obesity, but it seems almost impossible to do this in advanced obesity. Obesity is a disease that should be struggled with because of the high cost of treatment with the comorbidities. Surgical treatment is an appropriate and effective option in the treatment of this endemic disease which causes early death due to its comorbidities. ${ }^{[5,6]}$ Surgical treatment of morbid obesity is called bariatric surgery. All morbid obese patients have high risk for bariatric surgery. These risks should be considered when planning surgical treatment. In the treatment of morbid obesity, the surgeon needs the relative consultant specialist physicians, operating room conditions, equipments and adequate follow-up opportunities. Multidisciplinary approach is important. Bariatric surgery has been applied in the treatment of hyperlipidemia syndromes in the 1950s and different surgical methods have been defined. The most commonly used procedures worldwide are Roux-en Y gastric bypass (RYGB) and adjustable gastric banding (AGB). Biliopancreatic diversion/duodenal switch (BPD-DS) is a less common method. Sleevegastrectomy (SG) has been a rapidly growing initiative worldwide. SG has taken its place among the metabolic surgical procedures as well as RYGB, AGB and BPD-DS interventions due to its effectiveness in achieving and maintaining weight loss. In this study, we aimed to evaluate the pathology results of patients to whom SG was applied due to obesity in our hospital and who did not have stomach complaints before this operation.

\section{Materials and Methods}

\section{Study Design and Patients}

Pathology results of the patients who underwent laparoscopic sleevegastrectomy for obesity in the general surgery clinic of Şanlıurfa Training and Resarch Hospital between March 2018 and December 2018 were evaluated retrospectively. The study was made according to Helsinki Declaration. In our hospital, 107 patients were operated between these dates. Age, gender, body mass index (BMI) and pathology results of the patients were evaluated retrospectively via files and computer. As a criterion for operation; The patients with BMI $35 \mathrm{~kg} / \mathrm{m}^{2}$ and with medical comorbidities such as hypertension, diabetes mellitus and sleep apnea and patients with BMI $40 \mathrm{~kg} / \mathrm{m}^{2}$ and above were determined. All of our patients had previously tried diet, medical treatment, lifestyle changes, behavioral modifications and other conservative methods and failed to lose weight. All patients were consulted with psychiatry, chest diseases, cardiology, internal medicine or endocrinology clinics. Informed consent was obtained from the patient and/or relatives for the surgical intervention.

\section{Classification of Body Mass Index}

The BMI obtained from the anthropometric measurement, body weight and height measurements accepted by the World Health Organization in Obesity Studies is the most common and valid standard height-weight index applicable to all individuals without gender discrimination. In Table 1, patients are classified as weak, normal, overweight, obese according to the BMI values accepted by the World Health Organization. In addition, obese people can also be classified into groups. ${ }^{[7]}$

\section{Surgical Technique}

The surgical procedure was performed under general anesthesia in patients to whom LSG was applied. Twelve $\mathrm{mm}-\mathrm{Hg}$ intraabdominal pressure was used. The surgical procedure was performed with the help of 5 trochars. Trochar entries were as follows; $10 \mathrm{~mm}$ from subxiphoid, umbilicus and right subcostal midclavicular line (for liver retractor), $12 \mathrm{~mm}$ from left subcostal midclavicular line (for stapler access), $5 \mathrm{~mm}$ from left subcostal midline axillary line. With the help of Covidien ${ }^{\circledR}$ ligasure, the large curvature was released starting from 4-6 cm distal of pylorus to the His angle. Then, with the help of a $38 \mathrm{~F} \mathrm{spark}$

\section{Table 1. Obesity classification according to BMI}

\begin{tabular}{lc} 
Classification & BMI $\left(\mathbf{k g} / \mathbf{m}^{2}\right)$ \\
\hline Weak & $<18.5$ \\
Normal & $18.5-24.9$ \\
Overweight & $25-29.9$ \\
Obese & $\geq 30$ \\
$\quad$ Grade 1 & $30-34.9$ \\
Grade 2 & $35-39.9$ \\
\hline BMI: Body mass index. & \\
\hline
\end{tabular}


plug guidance, the stomach was resected including the fundus at a distance of 4-6 $\mathrm{cm}$ away from the pylorus. A narrow tubular stomach was created by this method. Hemostasis sutures were placed where necessary. Silicone abdominal drain was placed in all patients. Liquid foods were started at postoperative 3-4 days. No complications were observed peroperative and postoperative days.

\section{Statistical Analysis}

Statistical Package for the SocialSciences (SPSS 21 Inc., Chicago, IL, USA) computer software was used for bio-statistical analyses. Data presented as average values minimum-maximum values are also specified.

\section{Results}

A total number of 107 patients, who underwent sleevegastrectomy for morbid obesity between March 2018 and December 2018, were included in the study. The mean age of the patients was 36 (min: 20-max: 60 years). 81 of the patients were female and 26 were male. The mean BMI of the patients was 45.1 (min: 37.2-max: 63.4). When the pathology results of the patients were examined, the macroscopic size of the specimen was found as follows; the average length was $18.5 \mathrm{~cm}$ (min: $14 \mathrm{~cm}$-max: $25 \mathrm{~cm}$ ) and the average width was $4.2 \mathrm{~cm}$ (min: $3 \mathrm{~cm}$-max: $8 \mathrm{~cm}$ ). Normal gastric tissue was observed in 25 (23.3\%) patients in pathological examination. Chronic gastritis was found in $82(76.6 \%)$ patients. In 32 (29.9\%) patients with chronic gastritis diagnosis, Helicobacter pylori microorganism was found to be positive. Metaplasia was observed in $4(3.7 \%)$ of the patients with chronic gastritis. Atrophy was observed in 1 patient with chronic gastritis and foveolar hyperplasia was observed in 1 patient. Among the patients with positive chronic gastritis, 8 had lymphoid follicles, 1 had submucosal lipocytes, and 1 had parietal cell hyperplasia. A patient with suspected gastrointestinal stromal tumor during surgery was diagnosed as spindle cell mesenchymal lesion and chronic gastritis after pathological examination. Table 2 summarizes the demographic, clinical and histopathological characteristics of the patients. The patient's report after immunohistochemical staining was reported as a benign peripheral nerve sheath tumor with myxoid features. Liquid foods were started to patients at postoperative 3-4 days.

Table 2. The demographic, clinical and histopathological characteristics of the patients

\begin{tabular}{lc} 
Variable & $\mathbf{n}(\%)$ \\
\hline Age (mean) & 36 (min: 20 -max: 60 years) \\
Gender, $\mathrm{n}(\%)$ & $81(75.7)$ \\
$\quad$ Female & $26(24.2)$ \\
Male & 45.1 (min: 37.2 -max: 63.4$)$ \\
Body mass index $\left(\mathrm{kg} / \mathrm{m}^{2}\right)$ & \\
Macroscopic size of the specimen (mean) & $18.5 \mathrm{~cm}(\min : 14 \mathrm{~cm}$-max: $25 \mathrm{~cm})$ \\
Length & $4.2 \mathrm{~cm}(\min : 3 \mathrm{~cm}$-max: $8 \mathrm{~cm})$ \\
Width & \\
Histopathology, $\mathrm{n}(\%)$ & $25(23.3)$ \\
Normal gastric tissue & $82(76.6)$ \\
Chronic gastritis & $4(3.7)$ \\
Other histopathological findings, $\mathrm{n}(\%)$ & $1(0.9)$ \\
Metaplasia & $1(0.9)$ \\
Atrophy & $8(7.4)$ \\
Faveolar hyperplasia & $1(0.9)$ \\
Lymphoid follicles & $1(0.9)$ \\
Submucosal lipocytes & $1(0.9)$ \\
Parietal cell hyperplasia & \\
Spindle cell mesenchymal lesion & $32(29.9)$ \\
Helicobacter pylori, $\mathrm{n}(\%)$ & $75(70)$ \\
Positive & \\
Negative &
\end{tabular}




\section{Discussion}

Obesity is a chronic global health problem that adversely affects life and comfort. Obesity is increasing rapidly especially in young people and many chronic diseases are encountered at an earlier age. Gastrointestinal tract pathologies are an important risk factor for cardiac disorders, metabolic diseases, cancer and respiratory-rheumatologic-dermatological diseases. Gastro-esophageal reflux disease, esophagitis, hiatal hernia, esophageal carcinoma and $\mathrm{H}$. pylori infection have been reported to be two to three times more common in obese patients than people with normal weight. ${ }^{[8]}$ Although H.pylori has an effect on obesity development and increases the postoperative complications of obesity operations, it is not considered as a negative factor for obesity surgeries. ${ }^{[9]}$

There are few studies on the histopathological evaluation of LSG surgical specimens. In the study of Almazeedi et al., ${ }^{[10]}$ histopathology results were as following; 488 (74.4\%) patients with chronic gastritis, 63 (9.6\%) patients with follicular gastritis, $12(1.8 \%)$ patients with atrophic gastritis, $4(0.6 \%)$ cases of gastric polyps, $3(0.5 \%)$ cases of granulomatous disease and $1(0.2 \%)$ patient for each of the following diagnosis; gastro-intestinalstromal tumor, gastrointestinal autonomic nerve tumor, intestinalmethaplasia, collagenous gastritis and crypt cell apoptosis. H.pylori was detected in 48 patients (7.3\%).

In the study of Ohanessian et al., ${ }^{[11]}$ with 310 patients; the histopathologic findings included the following: no pathological alteration in 214 patients (69.0\%), chronic inactive gastritis in 41 (13.2\%), fundic gland polyp in 17 (5.5\%), proton pump inhibitor therapy effect in 12 (3.9\%), Helicobacter pylori (H. pylori)-associated chronic active gastritis in 10 (3.2\%), chronic active gastritis (H. pylori negative) in $5(1.6 \%)$, chronic gastritis with intestinal metaplasia in $4(1.0 \%)$, gastrointestinal stromal tumor (GIST) in $3(1.0 \%)$, and hyperplastic polyp, granulomatous inflammation, xanthogranulomatous inflammation, and mucosal ulceration in 1 patient each $(0.3 \%)$.

In the study of Miller et al., ${ }^{[12]}$ with 1463 patients; pathological findings were not present in $80.2 \%$ of patients. The most common changes are as follows; non-specific, Helicobacter-associated chronic gastritis (7.2\%), Helicobacter-associated gastritis (6.8\%), and benign fundic gland polyps (4.0\%). Other rare changes were lymphocytic gastritis, autoimmune atrophic gastritis, chronic gastritis with intestinal metaplasia, hyperplastic polyps, pancreatic heterotopia, GISTs and leiomyoma.

In the study of Solmaz et al., ${ }^{[13]}$ normal gastric tissue was observed in $57 \%$ of 816 patients. Gastritis not related with Helicobacter was observed in $14 \%(n=114)$ of the patients. H.pylori-associated gastritis was detected in $26 \%(n=212)$ of the cases and specific gastritis (lymphocytic gastritis) was detected in $0.36 \%(n=3)$. Intestinal metaplasia was observed in $2.64 \%$ ( $n=22)$.

It is still controversial whether routine preoperative upper gastrointestinal endoscopy should be performed in patients undergoing LSG. However, it should be done in symptomatic patients. Loewen et al. ${ }^{[14]}$ reported that endoscopy required medical treatment in $18 \%$ of patients prior to surgery; but surgical planning changed in $1 \%$ of patients. Preoperative routine upper gastrointestinal endoscopy provides the diagnosis of rare gastric pathologies. Preoperative management of these patients is an important factor affecting the success of bariatric surgery. Preoperative gastroscopy was not routinely performed to our patients.

When compared with the literature except Turkey, it was found to be less common than the normal gastric mucosa, but H.pylori-associated gastritis and $\mathrm{H}$. pylori has been found to be common than that reported in the literature. In a study of Arslan et al., ${ }^{[15]}$ with obese patients in Turkey; H.pylori prevalence was found to be $57.2 \%$ in obese patients. The prevelance of chronic gastritis in our study is higher than the prevelance of Turkey (76\%) and H.pylori prevelance was found to be lower than the Turkey's average (39\%).

Carabotti et al., ${ }^{[9]}$ found that postoperative complications were more common in obese patients with H.pylori infection. Almazeedi et al., ${ }^{[16]}$ found a $7.8 \%$ rate of Helicobacter pylori infection positivity in 680 LSG materials in their 2014 study. Although the presence of H. pylori was found to be high in our study, no significant relationship was found between the postoperative complications in patients.

The limition of our study was the low number of patients. The high number of $\mathrm{H}$. pylori positive patients was attributed to the nutritional habits of our region. We believe that $\mathrm{H}$. pylori infections do not have postoperative complication risk. However, we think that gastroscopy should be performed in patients with preoperative gastric complaints. 


\section{Disclosures}

Ethichs Committee Approval: Since it is a retrospective study, we did not apply for ethical committee approval. The study was made according to Helsinki Declaration.

Financial Disclosure: The authors declared that this study has received no financial support.

Peer-review: Externally peer-reviewed.

Conflict of Interest: None declared.

\section{References}

1. Obesity: preventing and managing the global epidemic. Report of a WHO consultation. World Health Organ Tech Rep Ser 2000;894:i-xii, 1-253.

2. McInnis KJ. Diet, exercise, and the challenge of combating obesity in primary care. J Cardiovasc Nurs 2003;18:93-100; quiz 101-2. [CrossRef]

3. Luyckx FH, Scheen AJ, Lefèbvre PJ. Non-alcoholic steatohepatitis. Lancet 1999;354:1298-9. [CrossRef]

4. World Health Organization. WHO global data base on body mass index.

5. Adams TD, Gress RE, Smith SC, Halverson RC, Simper SC, Rosamond WD, et al. Long-term mortality after gastric bypass surgery. N Engl J Med 2007;357:753-61. [CrossRef]

6. Schauer PR, Kashyap SR, Wolski K, Brethauer SA, Kirwan JP, Pothier $\mathrm{CE}$, et al. Bariatric surgery versus intensive medical therapy in obese patients with diabetes. $\mathrm{N}$ Engl J Med 2012;366:1567-76. [CrossRef]

7. World Health Organization. "Obesity: preventing and man- aging the global epidemic: report of a WHO consultation on obesity, Geneva, 3-5 June 1997." (1998).

8. De Palma GD, Forestieri P. Role of endoscopy in the bariatric surgery of patients. World J Gastroenterol 2014;20:7777-84.

9. Carabotti M, D'Ercole C, lossa A, Corazziari E, Silecchia G, Severi C. Helicobacter pylori infection in obesity and its clinical outcome after bariatric surgery. World $\mathrm{J}$ Gastroenterol 2014;20:647-53. [CrossRef]

10. Almazeedi S, Al-Sabah S, Al-Mulla A, Al-Murad A, Al-Mossawi A, Al-Enezi K, et al. Gastric histopathologies in patients undergoing laparoscopic sleeve gastrectomies. Obes Surg 2013;23:314-9. [CrossRef]

11. Ohanessian SE, Rogers AM, Karamchandani DM. Spectrum of Gastric Histopathologies in Severely Obese American Patients Undergoing Sleeve Gastrectomy. Obes Surg 2016;26:595-602. [CrossRef]

12. Miller GC, Reid AS, Brown IS. The pathological findings seen in laparoscopic sleeve gastrectomies for weight loss. Pathology 2016;48:228-32. [CrossRef]

13. Solmaz ÖA, Akyol H, Erol F. Histopathological findings and helicobacterpylori infection frequency in 816 sleeve gastrectomy materials for morbid obesity. Laparosc Endosc Surg Sci 2018;25:93-7. [CrossRef]

14. Loewen M, Giovanni J, Barba C. Screening endoscopy before bariatric surgery: a series of 448 patients. Surg Obes Relat Dis 2008;4:709-12. [CrossRef]

15. Arslan $E$, Atilgan $H$, Yavaşoğlu I. The prevalence of Helicobacter pylori in obese subjects. Eur J Intern Med 2009;20:695-7.

16. Almazeedi $\mathrm{S}, \mathrm{Al}$-Sabah $\mathrm{S}$, Alshammari D, Alqinai $\mathrm{S}, \mathrm{Al}-\mathrm{Mulla}$ A, Al-Murad A, et al. The impact of Helicobacter pylori on the complications of laparoscopic sleeve gastrectomy. Obes Surg 2014;24:412-5.[CrossRef] 